\title{
Hibiscus sabdariffa L. as a source of nutrients, bioactive compounds and colouring agents
}

\author{
Inès Jabeur ${ }^{\mathrm{a}}$, Eliana Pereira ${ }^{\mathrm{a}, \mathrm{b}}$, Lillian Barros ${ }^{\mathrm{a}}$, Ricardo C. Calhelha ${ }^{\mathrm{a}}$, Marina Sokovićc \\ M. Beatriz P.P. Oliveira ${ }^{\mathrm{b}}$, Isabel C.F.R. Ferreira ${ }^{\mathrm{a}, *}$ \\ a Centro de Investigação de Montanha (CIMO), Instituto Politécnico de Bragança, Campus de Santa Apolónia, 5300-253 Bragança, Portugal \\ ${ }^{\mathrm{b}}$ REQUIMTE/LAQV, Faculdade de Farmácia, Universidade do Porto, Rua Jorge Viterbo Ferreira no. 228, 4050-313 Porto, Portugal. \\ "Institute for Biological Research "Siniša Stanković", Department of Plant Physiology, University of Belgrade, Bulevar Despota Stefana 142, 11000 Belgrade, Serbia.
}

\section{A R T I C L E I N F O}

\section{Keywords:}

Hibiscus sabdariffa L.

Nutrients

Phenolic compounds

Antioxidants

Antimicrobials

\begin{abstract}
A B S T R A C T
The nutritional and bioactive composition of plants have aroused much interest not only among scientists, but also in people's daily lives. Apart from the health benefits, plants are a source of pigments that can be used as natural food colorants. In this work, the nutritional composition of Hibiscus sabdariffa L. was analysed, as well as its bioactive compounds and natural pigments. Glucose (sugar), malic acid (organic acid), $\alpha$-tocopherol (tocopherol) and linoleic acid (fatty acid) were the major constituents in the corresponding classes. 5(Hydroxymethyl) furfural was the most abundant non-anthocyanin compound, while delphinidin-3-O-sambubioside was the major anthocyanin both in its hydroethanolic extract and infusion. H. sabdariffa extracts showed antioxidant and antimicrobial activities, highlighting that the hydroethanol extract presents not only lipid peroxidation inhibition capacity, but also bactericidal/fungicidal inhibition ability for all the bacteria and fungi tested. Furthermore, both extracts revealed the absence of toxicity using porcine primary liver cells. The studied plant species was thus not only interesting for nutritional purposes but also for bioactive and colouring applications in food, cosmetic and pharmaceutical industries.
\end{abstract}

\section{Introduction}

Plants are rich sources of several classes of bioactive compounds that have been reported to be responsible in the prevention and treatment of chronic health pathologies such as hypertension, cardiovascular diseases, inflammation and cancer (Barata, Rocha, Lopes, \& Carvalho, 2016; Bresciani et al., 2015). Plants are also now being explored as sources of natural pigments to be used as food colorants, safer, with minimal toxic effects and displaying beneficial properties such as antioxidant and antimicrobial activities. Among the compounds present in plants with the potential to be used as colouring ingredients, anthocyanins emerge as promising molecules (Martins, Roriz, Morales, Barros, \& Ferreira, 2016).

Hibiscus sabdariffa L., also known as roselle, is an annual, herbaceous medicinal plant that belongs to the Malvaceae family. Despite being native to Asia, it is also widely cultivated in many areas, including Central America and Africa. This species is usually cultivated for its fibers and calyces, and includes three different genotypes: green, red (which is the most common type used) and dark red (Barhé \& Tchouya, 2015). The calyx is commercially important in the food industry for the production of beverages and foods such as tea, juices, jams, jellies and syrup (Borrás-Linares et al., 2015). The herbal tea of Hibiscus is commonly used around the world, as a sole ingredient in herbal infusions. In many countries, the leaves are also consumed as a leafy green vegetable (Zhen et al., 2016). Overall, there are several reports available on the consumption of the dried or fresh calyces, seeds and leaves of $H$. sabdariffa used in the preparation of herbal medicines, beverages and fermented drinks or even cooked raw (Da-Costa-Rocha, Bonnlaender, Sievers, Pischel, \& Heinrich, 2014). It is also rich in bioactive compounds such as anthocyanins and other flavonoids, organic acids and polysaccharides which are responsible for its antioxidant, antibacterial, anti-inflammatory, hepatoprotective and anticholesterol activities (Da-Costa-Rocha et al., 2014; Formagio et al., 2015). The composition of $H$. sabdariffa in terms of phenolic compounds has been previously analysed by some authors (Borrás-Linares et al., 2015; Christian \& Jackson, 2009). Moreover, Borrás-Linares et al. (2015), chemically characterized the $H$. sabdariffa ethanolic extract, reporting the presence of a great variety of phenolic compounds and organic acids, such as citric acid, hibiscus acid, hydroxycitric acid and protocatechuic acid, being the main phenolic acid present the latest

\footnotetext{
* Corresponding author.

E-mail address: iferreira@ipb.pt (I.C.F.R. Ferreira).
} 
mentioned compound, otherwise, quercetin glycosides and gossypetin were the major flavonoids found.

Anthocyanins are a group of phenolic compounds found in a wide variety of flowers and fruits presenting a reddish-purple colour and have been used as natural alternatives for the replacement of synthetic colouring additives in the food industry. The calyx of $H$. sabdariffa has been reported to contain delphinidin-3-glucoside, cyanidin-3-glucoside, delphinidin-3-sambubioside and cyanidin-3-sambubioside, being these compounds responsible for the red colour of this plant (Borrás-Linares et al., 2015). The intense red colour and some of the health promoting benefits of $H$. sabdariffa extracts, has triggered scientists to be more interested in exploiting this plant to obtain natural colouring ingredients for numerous applications in food industry (Frimpong, Adotey, Ofori-Kwakye, Lugrie-Kipo, \& Dwomo-Fokuo, 2014). Aside from their well reported colouring potential, these compounds have displayed bioactive properties such as antioxidant, anti-inflammatory, antibacterial, antitumor and hepatoprotective potential and as such they can act as multifunctional ingredients; as natural colorants as well as health promoting ingredients (Liu, Chang, Liu, \& Shen, 2016; Vagiri \& Jensen, 2017). Thus, the multifunctional properties (colorant and bioactive properties) of $H$. sabdariffa can be explored in the food and pharmaceutical industry, as natural ingredients to be incorporated into the food products (e.g. as a multifunctional ingrediente) and pharmaceutical industries (e.g. as a natural colorante and for its bioactive properties).

To the best of our knowledge, there is no research article in literature that reports a complete study on the chemical composition and bioactive properties of Hibiscus sabdariffa L. calyces. Thus, the present study provides the nutritional composition, and chemical characterization, regarding sugars, tocopherols, fatty acids, organic acids and phenolic compounds. Furthermore, bioactive properties, regarding antioxidant and antimicrobial activity of $H$. sabdariffa calyces were further explored. These results will demonstrate the multiple functional applications of this plant species, namely as a source of bioactive compounds, with antioxidant, antimicrobial activity and as a natural source of natural colouring compounds.

\section{Materials and methods}

\subsection{Samples}

Dried aerial parts of Hibiscus sabdariffa L., namely flowers and inflorescences, were provided by a local producer (Pragmático Aroma Lda, Alfândega da Fé, Bragança, Portugal), where the samples were air dried in order to obtain a constant weight measurement. The samples were reduced to a fine dried powder ( $\sim 20$ mesh), and mixed to obtain homogenous samples.

\subsection{Standards and reagents}

Acetonitrile $99.9 \%$, n-hexane $95 \%$ and ethyl acetate $99.8 \%$ were of HPLC grade from Fisher Scientific (Lisbon, Portugal). The fatty acid methyl ester (FAME) reference standard mixture (standard 47,885-U), $\mathrm{L}$-ascorbic acid, tocopherols ( $\alpha$-, $\beta-, \gamma$-, and $\delta$-isoforms), sugars (D $(-)$-fructose, $\mathrm{D}(+)$-sucrose, $\mathrm{D}(+)$-glucose, $\mathrm{D}(+)$-trehalose and $\mathrm{D}$ $(+)$-raffinose pentahydrate) and trolox (6-hydroxy-2,5,7,8-tetramethylchroman-2-carboxylic acid) were purchased from Sigma (St. Louis, MO, USA). Racemic tocol, $50 \mathrm{mg} / \mathrm{mL}$, was purchased from Matreya (Plesant Gap, PA, USA). 2,2-Diphenyl-1-picrylhydrazyl (DPPH) was obtained from Alfa Aesar. Fetal bovine serum (FBS), L-glutamine, Hank's balanced salt solution (HBSS), trypsin-EDTA (ethylenediaminetetraacetic acid), penicillin/streptomycin solution $(100 \mathrm{U} / \mathrm{mL}$ and $100 \mathrm{mg} / \mathrm{mL}$, respectively), RPMI-1640 and DMEM media were from Hyclone (Logan, Utah, USA). Acetic acid, ellipticine, sulforhodamine B (SRB), trypan blue, trichloroacetic acid (TCA) and Tris were supplied by Sigma Chemical Co. (Saint Louis, MO, USA). Water was treated in a
Milli-Q water purification system (TGI Pure Water Systems, Greenville, SC, USA).

\subsection{Nutritional composition}

The protein, fat, carbohydrates and ash content were estimated using the AOAC $(2016)$ procedures. The crude protein $(\mathrm{N} \times 6.25)$ was determined by the Kjeldahl method (991.02); the ash content (935.42) was estimated by subjecting the sample to incineration at $600 \pm 15^{\circ} \mathrm{C}$ for $5 \mathrm{~h}$, while the crude fat was determined using a Soxhlet apparatus with petroleum ether as recycling solvent (989.05) and total carbohydrate was estimated by difference. The total energy was calculated using the following equation: Energy $(\mathrm{kcal})=4 \times(\mathrm{g}$ protein $+\mathrm{g}$ carbohydrates $)+9 \times$ ( $\mathrm{g}$ fat $)$.

Free sugars were analysed by high performance liquid chromatography coupled to a refraction index detector (HPLC-RI), according to a procedure previously described by Pereira, Barros, and Ferreira (2015). Data were analysed using Clarity 2.4 Software (DataApex, Podohradska, Czech Republic) (fructose: $\mathrm{LOD}=0.05 \mathrm{mg} / \mathrm{mL}$; $\mathrm{LOQ}=0.18 \mathrm{mg} / \mathrm{mL} ;$ glucose: $\mathrm{LOD}=0.08 \mathrm{mg} / \mathrm{mL} ; \mathrm{LOQ}=0.25 \mathrm{mg}$ / $\mathrm{mL}$ ), and the results were expressed in $\mathrm{g}$ per $100 \mathrm{~g}$ of dry weight.

The organic acids were determined using the Ultra Fast Liquid Chromatography (UFLC, Shimadzu 20A series, Kyoto, Japan) and a photodiode array detector, according to a procedure previously described by Dias et al. (2013). The separation was achieved on a SphereClone reverse phase $\mathrm{C} 18$ column thermostatted at $35^{\circ} \mathrm{C}$ (oxalic acid: $\quad \mathrm{LOD}=12.55 \mu \mathrm{g} / \mathrm{mL} ; \quad \mathrm{LOQ}=41.82 \mu \mathrm{g} / \mathrm{mL} ; \quad$ malic $\quad$ acid: $\mathrm{LOD}=35.76 \mu \mathrm{g} / \mathrm{mL} ; \mathrm{LOQ}=119.18 \mu \mathrm{g} / \mathrm{mL} ; \mathrm{LOQ}=\mu \mathrm{g} / \mathrm{mL} ;$ fumaric acid: $\mathrm{LOD}=0.08 \mu \mathrm{g} / \mathrm{mL} ; \mathrm{LOQ}=0.26 \mu \mathrm{g} / \mathrm{mL}$ ). The results were expressed in $\mathrm{g}$ per $100 \mathrm{~g}$ of dry weight.

The fatty acids were determined by gas chromatography coupled with a flame ionization detector (GC-FID/capillary column, DANI model GC 1000, Contone, Switzerland), a split/splitless injector and a Macherey-Nagel column. The methodology followed a procedure previously described by Pereira et al. (2015) and the fatty acids were identified by comparing the relative retention times of FAME peaks from samples with commercial standards. The results were treated using the chromatography station for Windows CSW (version 1.7) software from DataApex (Podohradska, Czech Republic) and expressed in relative percentages.

The tocopherols were determined according to a method previously described by Pereira et al. (2015). A HPLC coupled to a fluorescence detector and programmed for excitation at $290 \mathrm{~nm}$ and emission at $330 \mathrm{~nm}$, was used. The quantification was carried out based on calibration curves obtained from commercial standards of each compound ( $\alpha$-tocopherol: $\quad$ LOD $=18.06 \mathrm{ng} / \mathrm{mL} ; \quad$ LOQ $=60.20 \mathrm{ng} / \mathrm{mL} ; \quad \beta$-tocopherol: $\mathrm{LOD}=25.82 \mathrm{ng} / \mathrm{mL} ; \mathrm{LOQ}=86.07 \mathrm{ng} / \mathrm{mL}$ ) and racemic tocol was used as the internal standard. The results were expressed in $\mathrm{mg}$ per $100 \mathrm{~g}$ of dry weight.

\subsection{Non-anthocyanin and anthocyanin compounds}

\subsubsection{Extraction preparation}

The hydroethanolic extract was prepared by using the dry sample $(1 \mathrm{~g})$ macerated with $30 \mathrm{~mL}$ of ethanol/water $(80: 20 \mathrm{v} / \mathrm{v}), 25^{\circ} \mathrm{C}$ at $150 \mathrm{rpm}$ for $1 \mathrm{~h}$ and subsequently filtered through Whatman No. 4 paper. The residue was then additionally extracted with $30 \mathrm{~mL}$ of the same solution $\left(25^{\circ} \mathrm{C}\right.$ at $\left.150 \mathrm{rpm}\right)$ for $1 \mathrm{~h}$. The combined extracts were evaporated at $40{ }^{\circ} \mathrm{C}$ and further lyophilized.

An infusion was also prepared by adding boiling distilled water $\left(100 \mathrm{~mL}\right.$, at $\left.100^{\circ} \mathrm{C}\right)$ to $500 \mathrm{mg}$ of the dry sample. Afterwards, it was let to stand for $5 \mathrm{~min}$ at room temperature and subsequently, filtered and then lyophilized according to a procedure described by Pires, Dias, Barros, and Ferreira (2017).

The lyophilized hydroethanolic and infusion extracts were re-dissolved in ethanol/water $(80: 20 \mathrm{v} / \mathrm{v})$ and water at $10 \mathrm{mg} / \mathrm{mL}$, 
respectively, for phenolic profile evaluation.

\subsubsection{HPLC-DAD-ESI/MSn analysis}

For both non-anthocyanin and anthocyanin compounds the chromatographic data was acquired from a Dionex Ultimate 3000 UPLC (Thermo Scientific, San Jose, CA, USA). This system consists of a diode array detector coupled to an electrospray ionization mass detector (LCDAD-ESI/MSn), a quaternary pump, an auto-sampler (kept at $5{ }^{\circ} \mathrm{C}$ ), a degasser and an automated thermostated column section (kept at $35^{\circ} \mathrm{C}$ ) and a Waters Spherisorb S3 ODS-2 $\mathrm{C}_{18}(3 \mu \mathrm{m}, 4.6 \times 150 \mathrm{~mm}$, Waters, Milford, MA, USA) column provided chromatographic separations. For non-anthocyanin compounds, the solvents used were (A) $0.1 \%$ formic acid in water and (B) acetonitrile. The gradient elution applied was: $15 \%$ B (0-5 min), $15 \%$ B to $20 \%$ B (5-10 min), 20-25\% B (10-20 min), $25-35 \%$ B (20-30 min), 35-50\% B (30-40 min), and the column was then re-equilibrated, using a flow rate of $0.5 \mathrm{~mL} / \mathrm{min}$ and with an injection volume of $10 \mu \mathrm{L}$.

For anthocyanin compounds, the solvents used were: (A) $0.1 \%$ trifluoroacetic acid in water and (B) acetonitrile. The gradient elution followed these parameters: $10 \%$ B for $3 \mathrm{~min}$, from 10 to $15 \%$ B for $12 \mathrm{~min}, 15 \%$ B for $5 \mathrm{~min}$, from 15 to $18 \%$ B for $5 \mathrm{~min}$, from 18 to $30 \%$ B for $20 \mathrm{~min}$, from 30 to $35 \% \mathrm{~B}$ for $5 \mathrm{~min}$, and from 35 to $10 \% \mathrm{~B}$ for $10 \mathrm{~min}$. Sixty minutes was the resulting total run time, followed by column reconditioning of $10 \mathrm{~min}$, using a flow rate of $0.5 \mathrm{~mL} / \mathrm{min}$ and with an injection volume of $10 \mu \mathrm{L}$. With a DAD, data were collected for both non anthocyanin compounds (280 nm and $370 \mathrm{~nm}$ ) and anthocyanin compounds at $520 \mathrm{~nm}$. In a mass spectrometer (MS) detection (Linear Ion Trap LTQ XL mass spectrometer, ThermoFinnigan, San Jose, CA, USA) negative mode was chosen for non-anthocyanin compounds whereas positive mode was selected for anthocyanin compounds. Retention times, UV-VIS and mass spectra were compared with available standards and with literature data, in order to identify the compounds. Calibration curves of available phenolic standards were constructed based on the UV signal to perform quantitative analysis. In the case of unavailable commercial standards, the compounds were quantified via calibration curve of the most similar standard available. The results were expressed as $\mathrm{mg} / \mathrm{g}$ of dry extract.

\subsection{Bioactivity evaluation}

The hydroethanolic and infusion lyophilized extracts were, respectively, re-dissolved in ethanol/water $(80: 20 \mathrm{v} / \mathrm{v})$ and water at $10 \mathrm{mg}$ / $\mathrm{mL}$ for antioxidant and antimicrobial assays, and at $8 \mathrm{mg} / \mathrm{mL}$ for cytotoxicity evaluation. The stock solutions were diluted to different concentrations to be submitted to different in vitro bioactivity evaluation assays.

The antioxidant activity (DPPH radical-scavenging activity, reducing power, $\beta$-carotene bleaching inhibition and TBARS formation inhibition) was evaluated by colorimetric assays, previously described by Jabeur et al. (2016). Trolox, a water-soluble analogue of vitamin E, was used as a positive control. The results were expressed in $\mathrm{EC}_{50}$ values (sample concentration providing $50 \%$ of antioxidant activity or 0.5 of absorbance in the reducing power assay).

The antibacterial activity was performed following a methodology previously described by Carocho et al. (2015). Enterobacter cloacae (ATCC 35030), Salmonella typhimurium (ATCC 13311), Pseudomonas aeruginosa (ATCC27853), Escherichia coli (ATCC (American type culture collection) 35210), were the tested Gram-negative bacteria, while Listeria monocytogenes (NCTC (National collection of type cultures) 7973), Micrococcus flavus (ATCC 10240), Bacillus cereus (clinical isolate) and Staphylococcus aureus (ATCC 6538) were the tested Gram-positive bacteria. Minimum inhibitory (MIC) and minimum bactericidal (MBC) concentrations were determined by using the microdilution method.

For the antifungal activity, the procedure previously described by Carocho et al. (2015) was followed by using these microfungi: Aspergillus ochraceus (ATCC 12066), Aspergillus versicolor (ATCC 11730),
Aspergillus niger (ATCC 6275), Aspergillus fumigatus (ATCC 1022), Trichoderma viride (IAM-Culture Collection, Center for Cellular and Molecular Research, Institute of Molecular and Cellular Biosciences, The University of Tokyo, Japan), Penicillium funiculosum (ATCC 36839), $P$. ochrochloron (ATCC 9112) and P. verrucosum var. cyclopium (food isolate). Minimum inhibitory (MIC) and minimum fungicidal (MBF) concentrations were also determined by using the microdilution method.

A porcine liver primary cells culture, established in our laboratory (PLP2), was used to evaluate the hepatotoxicity of the extracts, following a previously described methodology (Rodrigues et al., 2012). The results were expressed in $\mathrm{GI}_{50}$ values, i.e. the extract concentration that inhibited $50 \%$ of the net cell growth. Ellipticine was used as positive control.

\subsection{Statistical analysis}

Three samples were used to obtain the extracts also in triplicate, and all the assays were carried out in triplicate. The results were expressed as mean values and standard deviation (SD) and analysed using a Student's $t$-test, in order to determine the significant difference among the different extracts (hydroethanolic or infusion), with $\alpha=0.05$. This treatment was made using SPSS v. 23.0 program.

\section{Results and discussion}

\subsection{Nutritional properties}

The results of the nutritional composition of Hibiscus sabdariffa L. are shown in Table 1. Carbohydrates were the most abundant macronutrients, followed by ash, proteins and fat. The nutritional profile of $H$. sabdariffa was reviewed by Ismail, Ikram, and Nazri (2008); despite some slight differences in the concentration of several macronutrients, which can be attributed to environmental factors, carbohydrates were also the most abundant macronutrients, followed by proteins and fat.

Fructose and glucose were the two free sugars found in the sample, glucose being the most abundant molecule $(6.5 \mathrm{~g} / 100 \mathrm{~g} \mathrm{dw})$. According to other authors, these monosaccharides show benefits related with prolonged exercise performance (Rosset, Egli, \& Lecoultre, 2017), due to the fact that these molecules induce a spectrum of effects on the muscle metabolism, possibly resulting in an improved performance (Rosset et al., 2017).

Oxalic, malic, shikimic and fumaric acids were the main organic acids identified and quantified (Table 1), malic acid (9.10 g/100 g dw) being the most abundant one. This acid has been reported to present some health benefits, namely its capacity to reduce the risk of metal poisoning, privilege fluidity, support the maintenance of oral health and increase immunity (Hossain, Akhtar, \& Anwar, 2015). Therefore, this plant species could be industrially exploited for production of malic acid as well as its derivatives due to their medicinal benefits (Miglio, Veglia, \& Fantozzi, 2015; Lin-Holderer, Li, Gruneberg, Marti, \& Kunze, 2016). Nevertheless, other organic acids were previously described on this species, such as, citric, hydroxycitric, hibiscus, tartaric and ascorbic acids (Da-Costa-Rocha et al., 2014), which were not present in the herein studied sample. The observed differences could be related with the production of different metabolites in response to environment changes, so the same plant species grown in different geographic areas may produce different compounds (Santos, Manuela, \& Saraiva, 2016).

$\alpha$ - and $\beta$-Tocopherols were the tocopherol isoforms found in $H$. sabdariffa, with $\alpha$ - isoform being the most abundant $(39.19 \mathrm{mg}$ / $100 \mathrm{~g} \mathrm{dw}$; Table 1). Tocopherols have received increased attention because of their well-reported antioxidant activity, being consumed as an exogenous source of antioxidants to reduce oxidative stress and to prevent several chronic diseases (Shahidi \& Camargo, 2016). Up to 18 fatty acids were also identified (Table 1), in which polyunsaturated fatty acids (PUFA) predominated over saturated fatty acids (SFA) and monounsaturated fatty acids (MUFA). Linoleic acid (C18:2n6) was the 
Table 1

Nutritional composition of Hibiscus sabdariffa L. (mean \pm DS).

\begin{tabular}{|c|c|c|c|}
\hline Nutritional value & & Fatty acids (\%) & \\
\hline Ash $(g / 100 \mathrm{~g} \mathrm{dw})$ & $7.4 \pm 0.5$ & Caproic acid (C6:0) & $0.40 \pm 0.02$ \\
\hline Proteins $(\mathrm{g} / 100 \mathrm{~g} \mathrm{dw})$ & $5.5 \pm 0.4$ & Caprylic acid (C8:0) & $0.14 \pm 0.01$ \\
\hline Fat $(g / 100 \mathrm{~g} \mathrm{dw})$ & $0.47 \pm 0.08$ & Capric acid (C10:0) & $0.220 \pm 0.001$ \\
\hline Carbohydrates $(\mathrm{g} / 100 \mathrm{~g} \mathrm{dw})$ & $87 \pm 1$ & Lauric acid (C12:0) & $0.47 \pm 0.03$ \\
\hline Energy (kcal/100 g dw) & $373 \pm 2$ & Myristic acid (C14:0) & $1.24 \pm 0.01$ \\
\hline Sugars Content $(\mathrm{g} / 100 \mathrm{~g} \mathrm{dw})$ & & Pentadecanoic acid (C15:0) & $0.84 \pm 0.01$ \\
\hline Fructose & $4.6 \pm 0.3$ & Palmitic acid (C16:0) & $27.73 \pm 0.02$ \\
\hline Glucose & $6.5 \pm 0.6$ & Palmitoleic acid (C16:1) & $1.32 \pm 0.04$ \\
\hline Sum & $11.1 \pm 0.9$ & Heptadecanoic acid (C17:0) & $1.28 \pm 0.06$ \\
\hline Organic acids Content ( $\mathrm{g} / 100 \mathrm{~g} \mathrm{dw})$ & & Stearic acid (C18:0) & $4.46 \pm 0.01$ \\
\hline Oxalic acid & $1.81 \pm 0.05$ & Oleic acid (C18:1n9) & $9.1 \pm 0.1$ \\
\hline Malic acid & $9.10 \pm 0.09$ & Linoleic acid (C18:2n6) & $32.65 \pm 0.07$ \\
\hline Shikinic acid & $0.356 \pm 0.002$ & $\alpha$-Linolenic acid (C18:3n3) & $15.76 \pm 0.04$ \\
\hline Fumaric acid & $0.043 \pm 0.002$ & Arachidic acid (C20:0) & $1.02 \pm 0.05$ \\
\hline Sum & $11.31 \pm 0.04$ & Eicosenoic acid (C21:0) & $0.21 \pm 0.02$ \\
\hline Tocopherols (mg/100 g dw) & & Behenic acid (C22:0) & $1.40 \pm 0.02$ \\
\hline$\alpha$-Tocopherol & $39.19 \pm 0.06$ & Tricosanoic acid (C23:0) & $0.67 \pm 0.01$ \\
\hline$\beta$-Tocopherol & $0.76 \pm 0.06$ & Lignoceric acid (C24:0) & $1.08 \pm 0.02$ \\
\hline \multirow[t]{3}{*}{ Sum } & $39.95 \pm 0.01$ & SFA & $41.2 \pm 0.1$ \\
\hline & & MUFA & $10.4 \pm 0.2$ \\
\hline & & PUFA & $48.4 \pm 0.1$ \\
\hline
\end{tabular}

SFA- Saturated fatty aids; MUFA- Monounsaturated fatty acids; PUFA- Polyunsaturated fatty acids.

major fatty acid (32.65\%) in the sample and, consequently, contributes to the higher levels of PUFA. This molecule displays health-promoting benefits in cancer prevention, reduction in body fat causing decrease in obesity, anti-inflammatory properties and resolving the severity of atherosclerosis and diabetes (Yang et al., 2015). Other PUFAs have been reported to display multiple physiological functions such as promoting normal human metabolism, immunomodulation and prevention of cardiovascular diseases and cancer (Pelliccia et al., 2013).

In sum, this study will provide a complete chemical characterization, due to the fact that to the best of our knowledge, neither sugars, nor tocopherols or fatty acids have been previously described in $H$. sabdariffa.

\subsection{Phenolic characterization}

Peak characteristics, tentative identities and phenolic compounds quantification are presented in Table 2. A chromatographic profile of the anthocyanin profile of $H$. sabdariffa hydroethanol extract is presented in Fig. 1.

Compounds 4 (5-O-caffeoylquinic acid), 7 (quercetin-3-O-rutinoside), 8 (quercetin-3-O-glucoside) and 9 (kaempferol-3-O-rutinoside) were positively identified by comparison with authentic standards, as also by their MS fragmentation pattern, retention time and UV-VIS characteristics. Compound 4 was previously identified by Peng et al. (2011) in the methanol extract of $H$. sabdariffa dried calyx. BeltranDebon et al. (2010), reported the presence of compounds 7 and 8 in infusions prepared from the calyces of $H$. sabdariffa, while HerranzLópez et al. (2012) described the presence of compound 9 in aqueous and ethanol extracts prepared from dried calyces of $H$. sabdariffa.

Compound $1\left([\mathrm{M}-\mathrm{H}]^{-}\right.$at $m / z$ 353) was identified as 3-O-caffeoylquinic acid based on its fragmentation pattern, yielding a base peak at $\mathrm{m} / z 191$ (deprotonated quinic acid) and an ion at $m / z 179$ [caffeic acid$\mathrm{H}]^{-}$with an intensity of $47 \%$ of the base peak, as reported by Clifford, Johnston, Knight, and Kuhnert (2003); Clifford, Johnston, Knight, and Kuhnert (2005). Similarly, compound $3\left([\mathrm{M}-\mathrm{H}]^{-}\right.$at $m / z$ 353) was tentatively identified according to its $\mathrm{MS}^{2}$ fragmentation as 4-O-caffeoylquinic acid (Clifford et al., 2003; Clifford et al., 2005). Meanwhile, compound $2\left([\mathrm{M}-\mathrm{H}]^{-}\right.$at $\mathrm{m} / \mathrm{z}$ 127) consisted of a 5-(hydroxymethyl) furfural, taking into account the findings described by Zhen et al. (2016), who studied the phenolic compounds profile of $H$. sabdariffa leaves. These same authors also reported the presence of the different chlorogenic acids described above (neochlorogenic, chlorogenic and cryptochlorogenic acids).

Compounds $5\left([\mathrm{M}-\mathrm{H}]^{-}\right.$at $\left.m / z 611\right)$ and $6\left([\mathrm{M}-\mathrm{H}]^{-}\right.$at $\left.m / z 595\right)$ presented UV spectra $\left(\lambda_{\max } 350-354 \mathrm{~nm}\right)$ and the production of a unique fragment ion at $m / z 317$ ([myricetin- $\mathrm{H}]^{-}$) and 301 ([quercetin$\mathrm{H}]^{-}$), releasing $-294 \mu$, that could correspond to a pentosyl $(-132 \mu)$ and hexosyl $(-162 \mu)$ moiety. Therefore, these compounds were tentatively identified as myricetin- $O$-pentosylhexoside and quercetin-Opentosylhexoside, respectively.

The anthocyanin compounds (peaks 10-13) were identified taking into account the identifications performed by Abdel-Moemin (2016) and Sinela et al. (2017), being identified as delphinidin-3-O-sambubioside (peak 10), delphinidin-3-O-glucoside (peak 11) and cyanidin-3$O$-sambubioside (peak 13). The most abundant compounds present in both extracts were 5-(hydroxymethyl) furfural and delphinidin-3-Osambubioside, as also described by Abdel-Moemin (2016) and Sinela et al. (2017). According to several studies, these two compounds have been previously reported to have bioactive potential. 5-(Hydroxymethyl) furfural has shown pharmacological effects, such as antioxidant, antiischemic, and antityrosine enzyme effects, improving blood rheology, and affecting the role of glycyrrhizin metabolism (Zhao et al., 2013). Also, delphinidin has demonstrated several biological activities, such as antioxidant, antimutagenesis, anti-inflammatory and anti-angiogenic properties. The mechanism of action of delphinidin acts through the vascular endothelial growth factor receptor-2 phosphorylation inhibition, platelet-derived growth factor ligand/receptor signaling, cancer cell proliferation and modulation of Met receptor phosphorylation (Patel, Jain, \& Patel, 2013). Nonetheless, to the best of our knowledge, myricetin glycoside derivatives and 5-(hydroxymethyl) furfural (the main compound) were not previously described in $H$. sabdariffa dried calyx.

\subsection{Bioactive properties}

The antioxidant activity of $H$. sabdariffa hydroethanol and infusion extracts was evaluated using four different in vitro assays. The results are shown in Table 3. Both extracts revealed antioxidant potential, thus presenting statistically significant differences ( $p$-value $<0.05$ ) between both extracts in all the assays. The highest antioxidant activity (lowest $\mathrm{EC}_{50}$ values) for DPPH and reducing power was obtained for infusions $(1.26$ and $0.54 \mathrm{mg} / \mathrm{mL}$, respectively). Otherwise, the 
Table 2

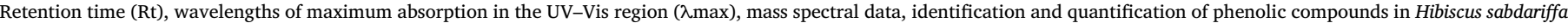
L. lyophilized hydroethanolic and infusion extracts (mean $\pm \mathrm{SD}$ ).

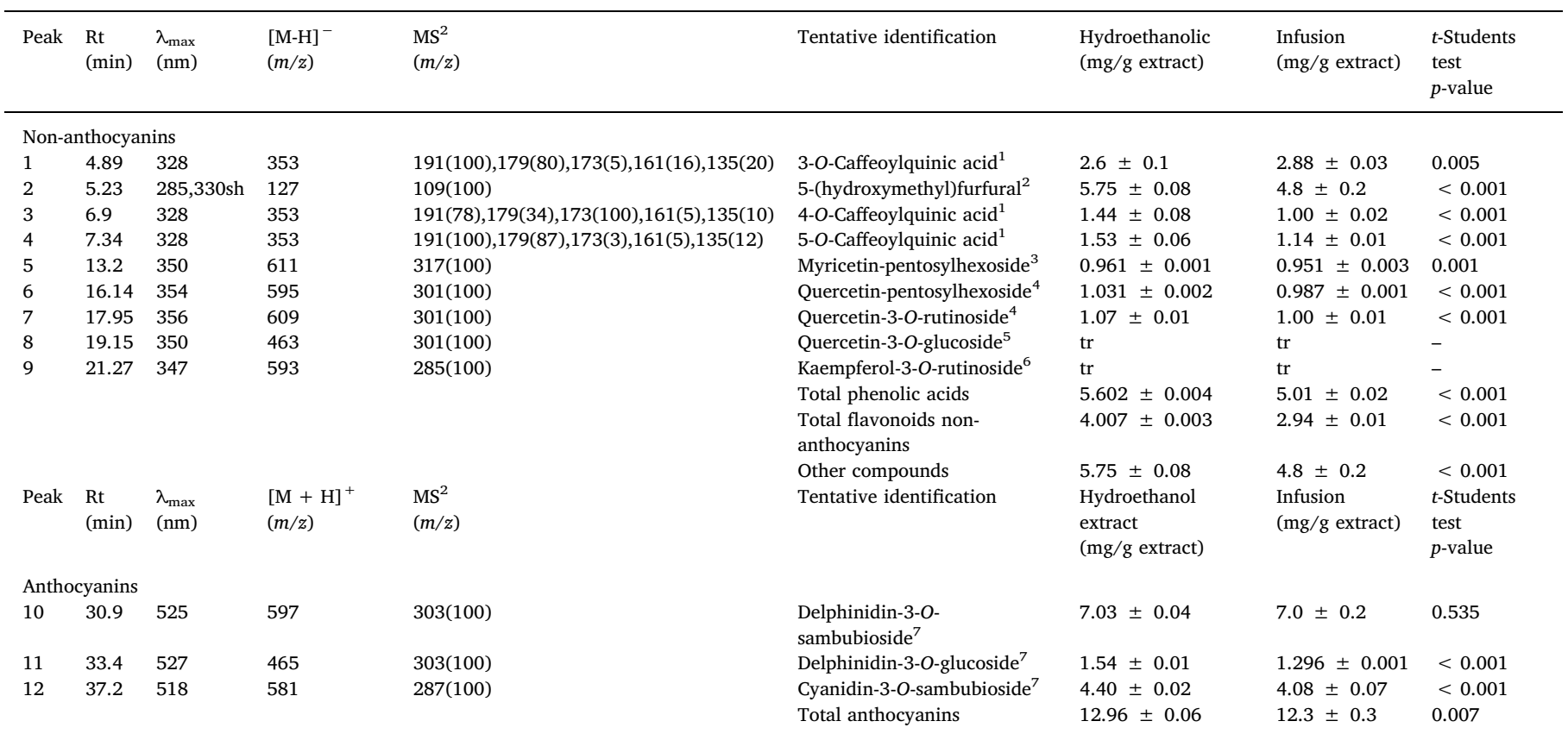

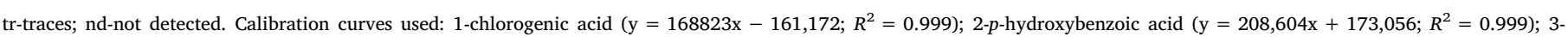

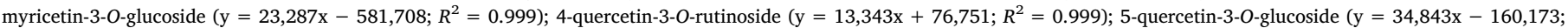
$\left.R^{2}=0.999\right) ; 6$-kaempferol-3-O-rutinoside $\left(\mathrm{y}=11,117 \mathrm{x}+30,861 ; R^{2}=0.999\right) ; 7$-cyaniding-3-O-glucoside $\left(\mathrm{y}=243,287 \mathrm{x}-1 \mathrm{E}+06 ; R^{2}=0.995\right)$.

hydroethanol extract revealed the highest antioxidant activity (1.95 and $0.26 \mathrm{mg} / \mathrm{mL}$, respectively), for the $\beta$-carotene bleaching and TBARS formation inhibition assays (both related with lipid peroxidation processes).

In order to obtain this beneficial effect with the consumption of this plant as an infusion, and considering the highest mentioned $\mathrm{EC}_{50}$ values (results obtained from the inhibition of $\beta$-carotene bleaching inhibition) and extraction yields, a portion of $6.2 \mathrm{mg}$ of $H$. sabdariffa calyces $/ \mathrm{mL}$ would be necessary. Therefore, consumers when preparing a tea cup of $H$. sabdariffa calyces in the normal recommended doses $(1 \mathrm{~g}$ in $100 \mathrm{~mL}$, as suggested in tea packaging labels), will be incorporating 1.6 times the $\mathrm{EC}_{50}$ value obtained for antioxidant activity, which could provide this bioactivity. Regarding the extract, to obtain the beneficial effects, its consumption could be obtained by its incorporation in a food product, in which the highest concentration obtained in the antioxidant activity, could be used to estimate the amount to be incorporated in the product.

Different authors have previously described in vitro and in vivo antioxidant properties of $H$. sabdariffa extracts using different extraction solvents. Tsai, McIntosh, Pearce, Camden, and Jordan (2002) tested this action in water and methanol extracts, while Borrás-Linares et al. (2015) used a maceration with acidified ethanol. Mohd-Esa, Hern, Ismail, and Yee (2010) evaluated the aqueous extract and $80 \%(v / v)$ methanol extract, by studying the $\beta$-carotene bleaching inhibition and the DPPH radical-scavenging activity, while Sindi, Marshall, and Morgan (2014) used water, methanol, ethyl acetate or hexane extract and described a strong correlation between the antioxidant activity and the phenolic content.

To the best of our knowledge, none of the previous mentioned studies used an ethanol/water extraction mixture, which is considered a green solvent. It should be also be highlighted that, in the present study, no toxicity (tested in porcine liver cells) was observed for $H$. sabdariffa hydroethanol and infusion extracts, up to the maximal tested concentration of $400 \mu \mathrm{g} / \mathrm{mL}$ (Table 3). These assays were performed according with the National Cancer Institute guidelines.

The results on antibacterial and antifungal activities of $H$. sabdariffa hydroethanol and infusion extracts are presented in Table 4. The samples were tested against a panel of eight bacteria and fungi strains,

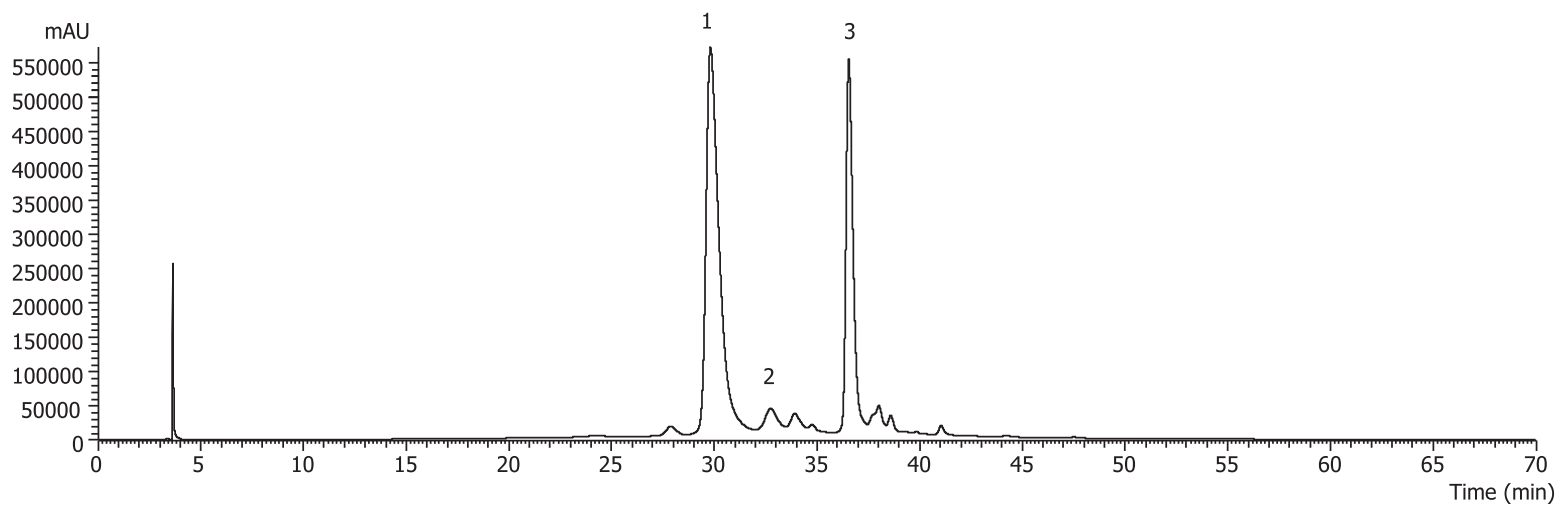

Fig. 1. Anthocyanins profile of Hibiscus sabdariffa L. hydroethanolic extract, recorded at $520 \mathrm{~nm}$. 
Table 3

Antioxidant activity of Hibiscus sabdariffa L. lyophilized hydroethanolic and infusion extracts (mean $\pm \mathrm{SD}$ ).

\begin{tabular}{|c|c|c|c|}
\hline & Hydroethanolic & Infusion & $\begin{array}{l}t \text {-Students } \\
\text { test } \\
p \text {-value }\end{array}$ \\
\hline \multicolumn{4}{|c|}{ Antioxidant activity $\left(\mathrm{EC}_{50}\right.$ values, $\left.\mathrm{mg} / \mathrm{mL}\right)$} \\
\hline $\begin{array}{l}\text { DPPH scavenging activity } \\
\text { (RSA) }\end{array}$ & $1.37 \pm 0.04$ & $1.26 \pm 0.05$ & $<0.001$ \\
\hline Reducing power (RP) & $0.603 \pm 0.002$ & $0.54 \pm 0.01$ & $<0.001$ \\
\hline $\begin{array}{c}\beta \text {-Carotene bleaching } \\
\text { inhibition (CBI) }\end{array}$ & $1.95 \pm 0.05$ & $4.2 \pm 0.2$ & $<0.001$ \\
\hline $\begin{array}{l}\text { TBARS formation inhibition } \\
\text { (LPI) }\end{array}$ & $0.26 \pm 0.01$ & $0.27 \pm 0.01$ & 0.015 \\
\hline \multicolumn{4}{|c|}{ Hepatotoxicity ( $\mathrm{GI}_{50}$ values, $\mathrm{mg} / \mathrm{mL}$ ) } \\
\hline PLP2 & $>0.4$ & $>0.4$ & - \\
\hline
\end{tabular}

$\mathrm{EC}_{50}$ values: Extract concentration corresponding to $50 \%$ of antioxidant activity or 0.5 of absorbance in reducing power assay. Trolox (positive control) $\mathrm{EC}_{50}$ values: $41 \mu \mathrm{g} / \mathrm{mL}$ (reducing power), $42 \mu \mathrm{g} / \mathrm{mL}$ (DPPH scavenging activity), $18 \mu \mathrm{g} / \mathrm{mL}$ ( $\beta$-carotene bleaching inhibition) and $23 \mu \mathrm{g} / \mathrm{mL}$ (TBARS inhibition). $\mathrm{GI}_{50}$ values: Extract concentration that inhibited $50 \%$ of the net cell growth in PLP2. Ellipticine (positive control) $\mathrm{GI}_{50}$ values: $2.29 \mu \mathrm{g} / \mathrm{mL}$.

Table 4

Antibacterial (MIC and MBC mg/mL) and antifungal (MIC and MFC mg/mL) activities of Hibiscus sabdariffa L. lyophilized hydroethanolic and infusion extracts.

\begin{tabular}{|c|c|c|c|c|c|c|c|c|c|}
\hline \multicolumn{10}{|c|}{ Antibacterial activity } \\
\hline \multirow{3}{*}{ Hydroethanolic } & & B.c. & M.f. & S.a. & L.m. & E.c. & En.cl. & P.a. & S.t. \\
\hline & MIC & 0.15 & 0.20 & 0.15 & 0.15 & 0.20 & 0.15 & 0.15 & 0.15 \\
\hline & MBC & 0.30 & 0.30 & 0.30 & 0.30 & 0.30 & 0.30 & 0.30 & 0.30 \\
\hline \multirow[t]{2}{*}{ Infusion } & MIC & - & - & 0.20 & 0.20 & - & 0.30 & 0.20 & 0.20 \\
\hline & MBC & - & - & 0.30 & 0.30 & - & - & 0.30 & 0.30 \\
\hline \multirow[t]{2}{*}{ Streptomycin } & MIC & 0.10 & 0.20 & 0.04 & 0.20 & 0.20 & 0.20 & 0.20 & 0.25 \\
\hline & MBC & 0.20 & 0.30 & 0.10 & 0.30 & 0.30 & 0.30 & 0.30 & 0.50 \\
\hline \multirow[t]{2}{*}{ Ampicillin } & MIC & 0.25 & 0.25 & 0.25 & 0.40 & 0.40 & 0.25 & 0.75 & 0.40 \\
\hline & MBC & 0.40 & 0.40 & 0.45 & 0.50 & 0.50 & 0.50 & 1.20 & 0.75 \\
\hline \multicolumn{10}{|c|}{ Antifungal activity } \\
\hline & & A.fum. & A.v. & A.o. & A.n. & T.v. & P.f. & P.o. & P.v.c. \\
\hline \multirow[t]{2}{*}{ Hydroethanolic } & MIC & 0.30 & 0.10 & 0.15 & 0.30 & 0.075 & 0.20 & 0.15 & 0.20 \\
\hline & MFC & 0.45 & 0.15 & 0.30 & 0.45 & 0.15 & 0.45 & 0.30 & 0.45 \\
\hline \multirow[t]{2}{*}{ Infusion } & MIC & 0.3 & 0.3 & - & 0.3 & 0.3 & - & 0.3 & 0.3 \\
\hline & MFC & - & - & - & - & - & - & - & \\
\hline \multirow[t]{2}{*}{ Ketoconazole } & MIC & 0.25 & 0.20 & 1.50 & 0.20 & 1.00 & 0.20 & 2.50 & 0.20 \\
\hline & MFC & 0.50 & 0.50 & 2.00 & 0.50 & 1.00 & 0.50 & 3.50 & 0.30 \\
\hline \multirow{2}{*}{ Bifonazole } & MIC & 0.15 & 0.10 & 0.15 & 0.15 & 0.15 & 0.20 & 0.20 & 0.10 \\
\hline & MFC & 0.20 & 0.20 & 0.20 & 0.20 & 0.20 & 0.25 & 0.25 & 0.20 \\
\hline
\end{tabular}

B.c.: Bacillus cereus; M.f.: Micrococcus flavus; S.a.: Staphylococcus aureos; L.m.: Listeria monocytogenes; E.c.: Escherichia coli; En. cl.: Enterobacter cloacae; P.a.: Pseudomonas aeruginosa; S.t.: Salmonella typhimirium; A.fum.: Aspergillus fumigatus; A.v.: Aspergillus versicolor; A.o.: Aspergillus ochraceus; A.n.: Aspergillus niger; T.v.: Trichoderma viride; P.f.: Penicillium funiculosum; P.o.: Penicillium ochrochloron; P.v.c.: Penicillium verrucosum var. cyclopium. MIC- minimum inhibitory concentration; MBC- minimum bactericidal concentration and MFC- minimum fungicidal concentration.

particularly selected on the basis of their relevance to public health.

The hydroethanol extract revealed the same bactericidal effect for all the tested bacteria, but the lowest MIC (minimum growth inhibitory concentrations) values were observed against Bacillus cereus, Staphylococcus aureus, Listeria monocytogenes, Enterobacter cloacae, Pseudomonas aeruginosa and Salmonela typhimurium. No growth inhibitory activity was observed for the infusion extract against Bacillus cereus, Micrococcus flavus and Escherichia coli, and no bactericidal effect was provided on Enterobacter cloacae, despite the capacity to inhibit its growth.

The hydroethanol extract showed antifungal activity against all the tested strains with fungicide effects in all cases. Trichoderma viride was the most susceptible strain to this extract (MIC $=0.075 \mathrm{mg} / \mathrm{mL}$ and $\mathrm{MFC}=0.15 \mathrm{mg} / \mathrm{mL}$ ). The same fungicidal effect was obtained for
Aspergillus versicolor $(0.15 \mathrm{mg} / \mathrm{mL})$. Otherwise, no fungicidal activity was achieved by the $H$. sabdariffa infusion for any of the studied strain, despite its capacity to inhibit the growth of Aspergillus fumigatus, A. versicolor, A. niger, Trichoderma viride, Penicillium ochrochloron and $P$. verrucosum strains (MICs $=0.3 \mathrm{mg} / \mathrm{mL}$ ).

The differences observed for the antimicrobial activity using the hydroethanolic extract and infusion could be attributed to the different concentrations of the identified phenolic compounds present in both extracts, which can also be ascribed to the different solvents' polarity used to obtain the extract. Moreover, in general both antibacterial and antifungal properties revealed a similar concentration range of inhibition.

A portion of $0.67 \mathrm{mg}$ of $H$. sabdariffa dry calyces/mL would be necessary to obtain the beneficial effects of the infusion, considering the highest mentioned MFC values and extraction yield, and taking into account the previously mentioned considerations. Therefore, consumers when preparing a tea-cup of infusions will be incorporating 15 times the necessary concentration to provide this bioactivity. As mentioned above to obtain this effect, for example in a food product, the extract, would have to be incorporated taking into account the highest obtained concentration (e.g. MFC), obtained in the antimicrobial activity in order to estimate the amount to be incorporated in the product.

There are previous reports on the antimicrobial activity of $H$. sabdariffa calyce extracts obtained with several kinds of extracts. Higginbotham, Burris, Zivanovic, Davidson, and Stewart (2014) evaluated the antimicrobial potential of aqueous extracts, while BorrásLinares et al. (2015) used an acidified ethanol extract, and Abdallah (2016) tested this action in methanolic extracts. Moreover, Wong, Lim, and Chan (2010) also described its antimicrobial activity against Grampositive and Gram-negative bacteria, using methanol extracts of leaves and calyces of different Hibiscus species. Elmanama, Alyazji, and AbuGheneima (2011) studied the methanol and water extracts of $H$. sabdariffa, obtained by a Soxhlet extraction, against a panel of fungi and bacteria, revealing a higher antifungal effect.

In sum, the antimicrobial properties of $H$. sabdariffa calyces could be attributed to the richness in phytochemical metabolites, such as phenolic acids (protocatechuic acid) and anthocyanins (delphinidin-3-Osambubioside and cyanidin-3-O-sambubioside), as also described by other authors (Gutiérrez-Alcántara et al., 2016; Liu, Tsao, \& Yin, 2005).

\section{Conclusions}

Overall, medicinal plants intervene in different systems of the organism providing several preventive and therapeutic actions, due to the presence of a diversity of nutritional and bioactive compounds. $H$. sabdariffa revealed the presence of several interesting compounds, such as tocopherols, phenolic acids and flavonoids, including three different anthocyanins. Furthermore, lyophilized hydroethanolic and infusion extracts prepared from this plant exhibited antioxidant, antibacterial and antifungal properties. The obtained results highlight the potential of this species to be used as a source of bioactive and natural colouring ingredients for exploitation in food and pharmaceutical industries, among others, besides its value as functional herbal beverage.

\section{Acknowledgements}

The authors are grateful to the Foundation for Science and Technology (FCT, Portugal) and FEDER under Programme PT2020 for financial support to CIMO (UID/AGR/00690/2013) and under Programme NORTE2020 for the project NORTE-01-0145-FEDER023289, as also for L. Barros contract. The authors are also grateful to the Interreg España-Portugal for financial support through the project 0377_Iberphenol_6_E. 


\section{Conflict of interest}

\section{The authors declare they have no conflict of interest.}

\section{References}

Abdallah, E. M. (2016). Antibacterial efficiency of the Sudanese Roselle (Hibiscus sabdariffa L.), a famous beverage from Sudanese folk medicine. Journal of Intercultural Ethnopharmacology, 5(2), 186.

Abdel-Moemin, A. R. (2016). Effect of Roselle calyces extract on the chemical and sensory properties of functional cupcakes. Food Science and Human Wellness, 5, 230-237.

AOAC (2016). AOAC official methods of analysis (20th ed.). AOAC International.

Barata, A. M., Rocha, F., Lopes, V., \& Carvalho, A. M. (2016). Conservation and sustainable uses of medicinal and aromatic plants genetic resources on the worldwide for human welfare. Industrial Crops and Products, 88, 8-11.

Barhé, T. A., \& Tchouya, G. R. F. (2015). Comparative study of the anti-oxidant activity of the total polyphenols extracted from Hibiscus Sabdariffa L., Glycine max L. Merr., yellow tea and red wine through reaction with DPPH free radicals. Arabian Journal of Chemistry, 9, 1-8.

Beltran-Debon, R., Alonso-Villaverde, C., Aragones, G., Rodriguez-Medina, I., Rull, A., Micol, V., et al. (2010). The aqueous extract of Hibiscus sabdariffa calices modulates the production of monocyte chemoattractant protein-1 in humans. Phytomedicine, 17, $186-191$.

Borrás-Linares, I., Fernández-Arroyo, S., Arráez-Roman, D., Palmeros-Suárez, P. A., Del Val-Díaz, R., Andrade-Gonzáles, I., \& Segura-Carretero, A. (2015). Characterization of phenolic compounds, anthocyanidin, antioxidant and antimicrobial activity of 25 varieties of Mexican Roselle (Hibiscus sabdariffa). Industrial Crops and Products, 69, 385-394.

Bresciani, L., Calani, L., Cossu, M., Mena, P., Sayegh, M., Ray, S., \& Del Rio, D. (2015). (Poly) phenolic characterization of three food supplements containing 36 different fruits, vegetables and berries. PharmaNutrition, 3, 11-19.

Carocho, M., Barros, L., Calhelha, R. C., Ćirić, A., Soković, M., Santos-Buelga, C., \& Ferreira, I. C. F. R. (2015). Melissa officinalis L. decoctions as functional beverages: A bioactive approach and chemical characterization. Food \& Function, 6, 2240-2248.

Christian, K. R., \& Jackson, J. C. (2009). Changes in total phenolic and monomeric anthocyanin composition and antioxidant activity of three varieties of sorrel (Hibiscus sabdariffa) during maturity. Journal of Food Composition and Analysis, 22, 663-667.

Clifford, M. N., Johnston, K. L., Knight, S., \& Kuhnert, N. (2003). Hierarchical scheme for LC-MSn identification of chlorogenic acids. Journal of Agricultural and Food Chemistry, 51, 2900-2911.

Clifford, M. N., Johnston, K. L., Knight, S., \& Kuhnert, N. A. (2005). Discriminating between the six isomers of dicaffeoylquinic acid by LC-MSn. Journal of Agricultural and Food Chemistry, 53, 3821-3832.

Da-Costa-Rocha, I., Bonnlaender, B., Sievers, H., Pischel, I., \& Heinrich, M. (2014). Hibiscus sabdariffa L. - A phytochemical and pharmacological review. Food Chemistry, 165, 424-443.

Dias, M. I., Barros, L., Duenas, M., Pereira, E., Carvalho, A. M., Alves, R. C., ... Ferreira, I. C. F. R. (2013). Chemical composition of wild and commercial Achillea millefolium L. and bioactivity of the methanolic extract, infusion and decoction. Food Chemistry, $141,4152-4160$.

Elmanama, A. A., Alyazji, A. A., \& Abu-Gheneima, N. A. (2011). Antibacterial, antifungal and synergistic effect of Lawsonia Inermis, Punica Granatum and Hibiscus sabdariffa. Annals of AlQuds Medicine, 7, 33-41.

Formagio, A., Ramos, D., Vieira, M., Ramalho, S. R., Silva, M. M., Zárate, N. A. H., .. Carvalho, J. E. (2015). Phenolic compounds of Hibiscus sabdariffa and influence of organic residues on its antioxidant and antitumoral properties. Brazilian Journal of Biology, 75, 69-75.

Frimpong, G., Adotey, J., Ofori-Kwakye, K., Lugrie-Kipo, S., \& Dwomo-Fokuo, Y. (2014). Potential of aqueous extract of Hibiscus sabdariffa calyces as coloring agent in three pediatric oral pharmaceutical formulations. Journal of Applied Pharmaceutical Science, 4, 001-007.

Gutiérrez-Alcántara, E. J., Rangel-Vargas, E., Gómez-Aldapa, C. A., Falfan-Cortes, R. N., Rodríguez-Marín, M. L., Godínez-Oviedo, A., \& Castro-Rosas, J. (2016). Antibacterial effect of roselle extracts (Hibiscus sabadariffa), sodium hypochlorite and acetic acid against multidrug-resistant salmonella strains isolated from tomatoes. Letters in Applied Microbiology, 62, 177-184.

Herranz-López, M., Fernández-Arroyo, S., Pérez-Sanchez, A., Barrajón-Catalán, E., Beltrán-Debón, R., Menéndez, J. A., \& Micol, V. (2012). Synergism of plant-derived polyphenols in adipogenesis: Perspectives and implications. Phytomedicine, 19, 253-261.

Higoinbotham, K. L., Burris, K. P., Zivanovic, S., Davidson, P. M., \& Stewart, C. N. (2014). Aqueous extracts of Hibiscus sabdariffa calyces as an antimicrobial rinse on hot dogs against listeria monocytogenes and methicillin-resistant Staphylococcus aureus. Food Control, 40, 274-277.

Hossain, M. F., Akhtar, S., \& Anwar, M. (2015). Nutritional value and medicinal benefits of pineapple. International Journal of Nutrition and Food Sciences, 4, 84.

Ismail, A., Ikram, E. H. K., \& Nazri, H. S. M. (2008). Roselle (Hibiscus sabdariffa L.) seeds nutritional composition protein quality and health benefits. Food, 2, 1-16.

Jabeur, I., Tobaldini, F., Martins, N., Barros, L., Martins, I., Calhelha, R. C., ... Ferreira, I C. F. R. (2016). Bioactive properties and functional constituents of Hypericum androsaemum L.: A focus on the phenolic profile. Food Research International, 89, $422-431$.

Lin-Holderer, J., Li, L., Gruneberg, D., Marti, H. H., \& Kunze, R. (2016). Fumaric acid esters promote neuronal survival upon ischemic stress through activation of the Nrf2 but not HIF-1 signaling pathway. Neuropharmacology, 105, 228-240.

Liu, K. S., Tsao, S. M., \& Yin, M. C. (2005). In vitro antibacterial activity of roselle calyx and protocatechuic acid. Phytotherapy Research, 19, 942-945.

Liu, S., Chang, X., Liu, X., \& Shen, X. (2016). Effects of pretreatments on anthocyanin composition, phenolics contents and antioxidant capacities during fermentation of hawthorn (Crataegus pinnatifida) drink. Food Chemistry, 212, 87-95.

Martins, N., Roriz, C. L., Morales, P., Barros, L., \& Ferreira, I. C. F. R. (2016). Food colorants: Challenges, opportunities and current desires of agroindustries to ensure consumer expectations and regulatory practices. Trends in Food Science \& Technology, $52,1-15$.

Miglio, G., Veglia, E., \& Fantozzi, R. (2015). Fumaric acid esters prevent the nlrp3 inflammasome-mediated and ATP-triggered pyroptosis of differentiated thp- 1 cells. International Immunopharmacology, 28, 215-219.

Mohd-Esa, N., Hern, F. S., Ismail, A., \& Yee, C. L. (2010). Antioxidant activity in different parts of roselle (Hibiscus sabdariffa L.) extracts and potential exploitation of the seeds. Food Chemistry, 122, 1055-1060.

Patel, K., Jain, A., \& Patel, D. K. (2013). Medicinal significance, pharmacological activities, and analytical aspects of anthocyanidins 'delphinidin': A concise report. Journal of Acute Disease, 13, 169-178.

Pelliccia, F., Marazzi, G., Greco, C., Franzoni, F., Speziale, G., \& Gaudio, C. (2013). Current evidence and future perspectives on n-3 PUFAs. International Journal of Cardiology, 170, S3-S7.

Peng, C. H., Chyau, C. C., Chan, K. C., Chan, T. H., Wang, C. J., \& Huang, C. N. (2011) Hibiscus Sabdariffa polyphenolic extract inhibits hyperglycemia, hyperlipidemia, and glycation-oxidative stress while improving insulin resistance. Journal of Agricultural and Food Chemistry, 59, 9901-9909.

Pereira, C., Barros, L., \& Ferreira, I. C. F. R. (2015). A comparison of the nutritional contribution of thirty-nine aromatic plants used as condiments and/or herbal infusions. Plant Foods for Human Nutrition, 70, 176-183.

Pires, T. C., Dias, M. I., Barros, L., \& Ferreira, I. C. (2017). Nutritional and chemical characterization of edible petals and corresponding infusions: Valorization as new food ingredients. Food Chemistry, 220, 337-343.

Rodrigues, S., Calhelha, R. C., Barreira, J. C., Dueñas, M., Carvalho, A. M., Abreu, R. M., \& Ferreira, I. C. (2012). Crataegus monogyna buds and fruits phenolic extracts: Growth inhibitory activity on human tumor cell lines and chemical characterization by HPLC-DAD-ESI/MS. Food Research International, 49, 516-523.

Rosset, R., Egli, L., \& Lecoultre, V. (2017). Glucose-fructose ingestion and exercise performance: The gastrointestinal tract and beyond. European Journal of Sport Science. http://dx.doi.org/10.1080/17461391.2017.1317035.

Santos, E. S., Manuela, M., \& Saraiva, J. A. (2016). Mutielemental concentration and physiological responses of Lavandula pedunculata growing in soils developed on different mine. Environmental Pollution, 213, 43-52.

Shahidi, F., \& Camargo, A. C. (2016). Tocopherols and tocotrienols in common and emerging dietary sources: Occurrence, applications, and health benefits. International Journal of Molecular Sciences, 17, 1-29.

Sindi, H. A., Marshall, L. J., \& Morgan, M. R. (2014). Comparative chemical and biochemical analysis of extracts of Hibiscus sabdariffa. Food Chemistry, 164, 23-29.

Sinela, A., Rawat, N., Mertz, C., Achir, N., Fulcrand, H., \& Dornier, M. (2017). Anthocyanins degradation during storage of Hibiscus sabdariffa extract and evolution of its degradation products. Food Chemistry, 214, 234-241.

Tsai, P. J., McIntosh, J., Pearce, P., Camden, B., \& Jordan, B. R. (2002). Anthocyanin and antioxidant capacity in Roselle (Hibiscus sabdariffa L.) extract. Food Research International, 35, 351-356.

Vagiri, M., \& Jensen, M. (2017). Influence of juice processing factors on quality of black chokeberry pomace as a future resource for colour extraction. Food Chemistry, 217, 409-417.

Wong, S. K., Lim, Y. Y., \& Chan, E. W. C. (2010). Evaluation of antioxidant, anti-tyrosinase and antibacterial activities of selected Hibiscus species. Ethnobotanical Leaflets, 14, 781-796.

Yang, B., Chen, H., Stanton, C., Ross, P., Zhang, H., Chen, Y. Q., \& Chen, W. (2015). Review of the roles of conjugated linoleic acid in health and disease. Journal of Functional Foods, 15, 314-325.

Zhao, L., Chen, J., Su, J., Li, L., Hu, S., Li, B., ... Chen, T. (2013). In vitro antioxidant and antiproliferative activities of 5-hydroxymethylfurfural. Journal of Agricultural and Food Chemistry, 44, 10604-10611.

Zhen, J., Villani, T., Guo, Y., Qi, Y., Chin, K., Pan, M.-H., ... Wu, Q. (2016) Phytochemistry, antioxidant capacity, total phenolic content and anti-inflammatory activity of Hibiscus sabdariffa leaves. Food Chemistry, 190, 673-680. 